\title{
Do OPERÁRIO PADRÃo AO Operário patrão
}

Ana Elizabete Mota

A atual conjuntura econômico-social e política do Brasil tornouse objeto de uma ampla discussão levada a efeito pelos mais diversos e até antagônicos setores da sociedade. Rompendo as fronteiras do Congresso Nacional, das Universidades, das entidades de classes e dos gabinetes ministeriais, ela ganha a rua no seu sentido mais preciso.

O fato de a esquerda não conseguir imprimir uma direção a este rico movimento, descaracterizando - de certa maneira - seu histórico papel de protagonista de um projeto social alternativo, causa perplexidade.

Partilhando de um discurso genérico, marcado essencialmente pelo balanço econômico da "década perdida" - ora tematizada como herança do modelo econômico implantado no pós-64, ora como produto do catastrofismo da crise global do capitalismo - as principais lideranças políticas da esquerda brasileira enfrentam a situação social do país sob o discurso da "retomada do crescimento econômico", tendo como estratégia a formação de alianças para sair da crise.

A referência jornalística da crise, tornada lugar comum, equaliza formulações e problemáticas que possuem gêneses absolutamente distintas. Sob a égide da crise são tratadas questões que vão do

Temáticas, Campinas, 2(3):109-122, jan./jun. 1994 
solapamento do projeto socialista até ao papel do Estado na regulação econômica e, mesmo, a questões como a fome, o desemprego e a corrupção. O que, longe de explicitar as particularidades da conjuntura brasileira, atua como o principal nutriente da formação de consensos acerca do "fim da história".

O discurso da crise ou sobre a crise é formador de uma cultura política que rebate no esgarçamento de referenciais teóricos, políticos e ideológicos, permitindo indicar alternativas à ordem do capital.

Os principais movimentos sociais surgidos no país durante o ano de 1994, provavelmente estarão destituídos do caráter de movimento das classes trabalhadoras, porque construídos sob a batuta de um suposto interesse geral da sociedade em denunciar a barbárie social brasileira. As campanhas "contra a fome", "pela ética na política" e "contra os massacres urbanos" etc., são exemplares do afirmado.

É inconteste o mérito de tais iniciativas, se analisadas do ponto de vista de uma solidariedade humana genérica ou mesmo da publicização das questōes sociais. No entanto, é necessário ir além das aparências e ultrapassar os objetivos prático-operativos destes movimentos, para percebê-los também como portadores de uma determinada cultura política que os diferencia radicalmente da experiência organizativa dos trabalhadores, construída ao longo da década de 80.

Refiro-me ao fato destes incorporarem - em larga medida um discurso salvacionista, de natureza transclassista, que sitia qualquer elemento de direção política explícita, como bem evidencia a sua auto-caracterização de movimentos supra-partidários, suprapolíticos, supra-ideológicos.

Assim, por mais visibilidade e impactos que produzam a divulgação da existência de 32 milhões de miseráveis ou a existência de focos de corrupção no Congresso, este conjunto de manifestações do fazer político burguês não foi suficiente para pôr a nu as determinações gerais e as particularidades da atual crise brasileira, 
nem sequer para evidenciar as formas estratégicas e táticas de seu enfrentamento.

Existe, portanto, um nexo entre a emergência destes movimentos e as tímidas e nebulosas propostas surgidas no âmbito dos sindicatos, centrais e partidos de esquerda que, neste momento, sofrem de uma profunda ausência de gerenciação.

Explorar esta crise de diferenciação como produto de uma cultura política da crise é o objetivo deste artigo. Sinteticamente: quero discutir a gestação de uma cultura política da crise. Defino-a, desde já, como um movimento formador de ideologias, valores e representações que procura tornar subjetiva a objetividade da ordem burguesa, tecendo a "espontaneidade racional" (GRAMSCI) da classe subalterna, ao imprimir ao ocasional e transitório o caráter de permanente.

Trata-se de um movimento molecular, isto é, daqueles "que envolvem os individuos $e$ os grupos modificando-os insensivelmente, no curso do tempo, de modo tal que o quadro de conjunto se modifica sem a aparente participação consciente dos atores sociais". (BADALONI, 1991:109)

Por isso, tal "cultura" pode ser formadora da hegemonia do grande capital e protagonista do consentimento ativo das classes subalternas, na medida que seja capaz de elaborar uma visāo socializadora da crise, conseguindo estruturar campos de lutas, indicar frentes consensuais de intervenção e demarcar espaços de alianças. (Cf. DIAS, 1993)

Essa cultura tenta construir um novo conformismo social, cujos interesses privados da classe burguesa devem se tornar genéricos e universais via saída conjunta para a crise neutralizando o patrimônio político-organizativo dos trabalhadores brasileiros, depois de uma década de lutas reativas e ofensivas sobre/contra o movimento ditatorial e concentrador do capital iniciado no pós 64 .

Temáticas, Campinas, 2(3):109-122, jan./jun. 1994 
Muitos cientistas sociais têm escrito e debatido sobre a crise dos anos 80 . Sem que se possa reproduzir nos limites deste artigo os diversos enfoques analíticos que sobre ela circulam faço algumas constataçōes a partir das quais é possível pensá-la como crise orgânica da sociedade contemporânea.

Refiro-me aqui à débâcle do socialismo real, ao esgotamento do Welfare State como um padrão de intervenção estatal nas sociedades desenvolvidas e ao sitiamento das alternativas econômicas para os países do Terceiro Mundo (em especial a América Latina). Este último, visível tanto nas pressões oriundas do monitoramento do seu endividamento externo, como nas injunções produzidas pela internacionalização do capital financeiro e pela re-divisão mundial da produção e dos mercados.

Este quadro objeto de diferentes óticas de análise , vem sendo discutido a partir de alguns eixos conceituais que o "politizam" no âmbito do discurso e dos projetos, tanto da direita, quanto da esquerda. Neste sentido, a categoria-chave do debate vem sendo a regulação estatal vis-a-vis a auto-regulação do mercado.

A polarização do debate entre socialismo-capitalismo vem sendo apresentada a partir da crítica aos papéis do Estado em detrimento de outras categorias de análise que lhes dariam inteligibilidade enquanto projetos societais.

Este enfoque reduz o conjunto das relações econômicas, sociais e políticas da sociedade contemporânea a uma mera implosão de modelos de intervenção estatal, estabelecendo uma causalidade mecânica entre crise e presença/ausência do Estado. Aqui, economicismo e politicismo se fundem, tendo como resultado o ocultamento das determinações fundamentais.

Deste prisma, pode-se dizer que no primeiro round da luta, a direita tem levado a melhor "na crise": não apenas porque vem conseguindo socializar a sua visão da crise, como porque, ao fazê-lo, parece estar imprimindo uma direção política que é constitutiva de sua tentativa de hegemonia - a formação de uma cultura da crise

Temáticas, Campinas, 2(3):109-122, jan./jun. 1994 
funcional aos seus interesses de classe. Parece, pois, que a direita conseguiu colocar a esquerda no canto do ringue!

Neste sentido, a adoção de um discurso acrítico sobre a crise e suas formas de superação, como parece estar acontecendo no Brasil, desemboca no que Conceição Tavares chama de estragos devastadores. Segundo Tavares (1991:53), "a idéia atual dos 'progressistas' é sua insistência na modernização, na inserção internacional dinâmica, na eficiência do Estado, como condições para empreender de novo o crescimento".

0 rebatimento da crise no Brasil se dá em dois planos gerais: um, determinado pelo sistema financeiro mundial e pelo reordenamento dos mercados e da produção internacionais, implicando essencialmente nos chamados ajustes econômicos (financiamentos, juros, importações/exportações etc.); o outro, referente à adoção de resoluções essencialmente políticas que dêem sustentação às medidas de ajuste.

O elenco dessas medidas é vasto, mas seu principal "gargalo" é a política de pactos entre empresários/governo/trabalhadores e a tentativa de revisão constitucional, que teria por objetivo sancionar mudanças de ordem legal-institucional relativas à entrada do capital estrangeiro, ao monopólio estatal da exploração do solo e à liberalização de algumas contribuições sociais vinculadas à folha de salário das empresas como é o caso da Previdência Social.

Certamente que algumas medidas de curto prazo nāo dependem da Revisão e já estão incorporadas à agenda governamental: as tentativas de saneamento do déficit público, a realização da reforma fiscal e a privatização de empresas produtivas estatais e de alguns serviços públicos na área da infra-estrutura.

Os rebatimentos da "crise", é claro, não se resumem à mera listagem dessas medidas. Estas indicações corroboram minha suposição de que, também no Brasil, o tratamento "da crise" - expresso no discurso e nos projetos do governo, dos partidos, dos empresários e... até de trabalhadores, particulariza um determinado modo de

Temáticas, Campinas, 2(3):109-122, jan./jun. 1994 
construção de uma cultura da crise nos marcos do pensamento neoliberal.

Tendo como sujeitos dominantes e dirigentes desse processo as classes proprietárias vinculadas ao setor industrial-financeiro e à burocracia estatal a eles associados, seu núcleo central se projeta na direção do desmonte dos mecanismos "democráticos".de regulação da produção social que "contenham qualquer componente (...) de controle do movimento do capital, em prol, é claro, dos seus intcresses particulares de classe". (NET'TO, 1993:81)

Avento a idéia de que se trata também, da gestação de uma cultura da "vontade corporativa", na medida que se funda em estreitas vinculações entre interesses imediatos do trabalhador e dos grandes ramos do complexo industrial e financeiro. Sua emergência se dá na exata medida em que parr afirmar a "vontade corporativa" é necessário negar, ainda que inconscientemente, a "vontade coletiva", articuladora de projetos de classe.

A "vontade coletiva" seguindo a tradição gramsciana é conceituada como "a consciência aluante da necessidade histórica, como protagonista de um drama histórico real e efetivo (...) no sentido de alcançar uma forma superior e total de civilização moderna". (GRAMSCI, 1988:7)

Ainda que a priori não encerre uma oposição, a "vontade corporativa" representa um movimento que aglutina interesses particulares e imediatos dos trabalhadores em função da sua inserção em uma mesma comunidade. No entanto, em níveis mais desenvolvidos essa "vontade corporativa" poderia configurar-se como uma "renúncia da hegemonia" 1 do coletivo de trabalhadores.

${ }^{1}$ Discutindo a história do conceito de hegemonia, Perry Anderson cita Lenin para demarcar a distinção entre a fase corporativa e fase hegemonica na ação política dos trabalhadores: "ć a consciència da idéia de hegemonia e a sua colocação em prática nas próprias atividades que transformam as corporaçōes no seu conjunto em uma classe". (ANDERSON, 1986:18). Sobre o tema, ver as próprias colocaçōes de Gramsci acerca do processo

Temáticas, Campinas, 2(3):109-122, jan./jun. 1994 
A burguesia tenta, assim, construir um novo conformismo baseado na fragmentação da vontade coletiva dos trabalhadores e na construçāo - para aqueles - de uma vontade corporativa sob a batuta do fracasso das experiências coletivistas do socialismo real e ancorados em uma suposta democratização do capital cujas regras não são construídas no espaço público, mas no âmbito de cada corporação ou, como se diz agora, mais "modernamente", de cada conglomerado em particular.

Sem subordinar a atividade crítica ao fatual, mas encarando-o como uma sinalização do real, vejo a experiência do Programa Nacional de Desestatização (PND) - principal explicitação do discurso da "modernização" do capitalismo brasileiro dos anos 90 , como referência para discutir uma das estratégias implementadas pelo Governo e pelos empresários e banqueiros para viabilizar a agenda da privatização: a adesão dos trabalhadores ao Programa. Fato que, desde já, considero um dos melhores produtos da cultura da crise.

Essa adesão dos trabalhadores é representada pela criação de um novo personagem no cenário social brasileiro - o "operário paträo" - que pode ser a versão pós-moderna do ex-operário padrão da ditadura ou do operário Brasil dos anos 80. Ambos patrocinados pelas Federações das Indústrias e pela Fundação Roberto Marinho.

Ironias à parte, o operário patrāo não é um desdobramento mecânico e linear do antigo operário-padrão. Embora sejam produtos de necessidades que nascem no mundo do trabalho - a disciplina taylorista dos anos 70 e a chamada flexibilização pós-fordista dos anos 90 - algo os separa definitivamente neste momento: a representação da sua inserção no salariato.

Enquanto os primeiros se reconheciam individual e coletivamente como vendedores de força de trabalho ao capital, como assalariados, os atuais trabalhadores-proprietários constroem uma antinomia so-

de construção da hegemonia, especificamente quando trata o "o momento econômico-corporativo" enquanto "expressão de uma relação de força". (GRAMSCI, 1988:49-51).

Temáticas, Campinas, 2(3):109-122, jan./jun. 1994 
bre a sua própria condição: trabalham como operários, mas devem se reconhecer como patrão apesar da sua participação acionária nas empresas não exceder $20 \%$ do capital. Aliás, esta foi a palavra de ordem veiculada na cidade de Timóteo (MG), quando terminou o pacífico leilão de privatização da Acesita. Alardeavam os autofalantes da Usina: "acionem as sirenes, pois agora o.peão vai ser patrão!”. Peão-patrão, patrão-peão, peão-patrão-de-peão, este é o único patrão do mundo que necessita de qualificativos ocupacionais, porque não é um patrão como os outros: provavelmente, além de peão, ele deve ser preto e pobre.

Sua condição de "patrão" não se dá em função do controle sobre o capital das empresas, mas pela sua condição simbólica de "dono" e pelo papel quase decisivo que têm desempenhado na formação dos consórcios e acordos de acionistas feitos com grandes grupos bancos, indústrias e construtoras que formam o novíssimo monopólio do aço no Brasil. Como diz a revista Veja, "os novos barões do aço, catedráticos em fortuna, o industrial Gerdau e o banqueiro Bozzano, agora têm trabalhadores como sócios das suas empresas". (Veja, 15-09-1993)

Lembremos, também, o recente consórcio formado pelos empregados da Açominas com a Mendes Júnior, a Villares, a White Martins e a Vale do Rio Doce, que promete ter o monopólio da fabricação de tarugos de aço, já que a $A$ çominas, com $67 \%$ do mercado, junta-se a Villares que também fabrica o mesmo produto.

Parece, pois, evidente que o atual operário patrão é um produto político da ação estratégica do capital, tanto quanto o foi o operário padrão. $\mathrm{O}$ que os distingue é o método de construção do esgarçamento das suas identidades de classe.

No primeiro caso, prevalecia a prática coercitiva - o modelo padrão de disciplina, da assiduidade, da produtividade e do puritanismo. No momento atual vale a persuasão, o convencimento, a elaboração de uma cultura dissolvedora da solidariedade inter-classe e restauradora da conciliação entre classes antagônicas, marcada pela

Temáticas, Campinas, 2(3):109-122, jan./jun. 1994 
formação de uma nova subjetividade: a condição comum de "ser patrāo". Ainda que trabalhe como peão, ganhe como peão, ele deve começar a pensar como patrão.

Sobre essa antinomia dos operários-padrão e patrão cabem, também, algumas considerações fatuais. Tome-se, por exemplo, a "pedagogia" da formação dos clubes de acionistas dos empregados. Os clubes de acionistas são instituições com personalidade jurídica que habilitam os empregados junto a Comissão de Valores Mobiliários (CVM) das Bolsas, para participar dos leilōes de privatização. Seu método de formação retrata bem esta dialética da destruição/contrução da solidariedade entre as classes trabalhadora e capitalista. Seu objetivo não é apenas a qualificação legalinstitucional do trabalhador como mais um agente do mercado, um potencial parceiro-investidor dos grandes grupos compradores. Sua finalidade é criar uma forma de organização por fora do espaço sindical, sem operar rupturas com os sindicatos para legitimar a privatização, criando, assim, a expressão material do consenso. Afinal, dizem os seus defensores: os trabalhadores estão salvando o emprego.

A formação dos clubes é a ante-sala de uma organização de "trabalhadores-proprietários" que, tão logo sejam acionistas, terão que consentir com as demissões pós-privatização e os planos de reestruturação da produção.

Os trabalhadores operam a lógica do "mal-menor"; suas justificações para participar deste processo são a crítica ao clientelismo e empreguismo da gestão estatal, a defesa do funcionamento das fábricas e a manutenção do emprego. Aliás, justificaçōes absolutamente pertinentes.

0 que causa espécie é o fato de que os criadores e gestores do clientelismo - os quadros dirigentes das estatais - não têm origem "de peão"; a acumulação do passivo e a política de subsídios nestas empresas também não foi opção "de peão", mas a salvação do emprego torna-se uma responsabilidade dele.

Temáticas, Campinas, 2(3):109-122, jan./jun. 1994 
Mas, tão logo o peão se reveste do estatuto de "dono", os argumentos da viabilidade econômica das empresas terminam por se sobrepor ao ideário da manutenção dos empregos. Assim, mais de 6000 trabalhadores foram despedidos destas ex-estatais e Vicentinho não precisou ir ao Vale do Aço! Não cabe, obviamente, nos limites deste artigo, uma reflexão cuidadosa sobre a questão das Câmaras Setoriais, aspecto particular deste tipo de saída para a crise.

De fato, a burguesia industrial e financeira, para além da sua condição de classe dominante, quer tornar-se classe dirigente obtendo o consentimento ativo de segmentos das classes subalternas em torno do núcleo mais duro do seu projeto: o Estado mínimo versus o mercado máximo, base da criação do cidadão-proprietárioconsumidor.

Ora, falar de Estado mínimo em um país cuja regulação estatal desde, pelo menos, o Plano de Metas de JK, foi sempre "truncada" (OLIVEIRA, 1990:44) porque destituida de regras, soa, no mínimo, estranho. Neste caso, tudo me leva a crer que a desregulamentação de que se fala no Brasil é apenas um código utilizado para qualificar a necessidade de reestruturação dos diversos capitais face as "novas demandas" da produção seletiva internacional em prol, é claro, da formação de novos nichos de acumulação, como é o caso da "oligopolização" da indústria do aço.

Não é a constatação do poder da burguesia para realizar redirecionamentos na intervenção do Estado na economia que ampara a minha argumentação da "gestação de uma cultura política da crise". Isto é inconteste. $\mathrm{O}$ novo, pelo contrário, reside no fato da burquesia não querer mais socializar "pelo alto" este poder. Isto é, para naturalizá-lo como expressão da sua ordem, além das condições materiais, é necessário tornar este projeto hegemônico. $\mathrm{O}$ eixo da adesão à sua ordem passa a ser: "acesso ao lucro para todos"!

Este processo não surgiu com o Programa de Privatização, como produto da eficiência pedagógica do governo Collor. Trata-se de um "movimento molecular", gestado a partir dos finais da década de

Temáticas, Campinas, 2(3):109-122, jan./jun. 1994 
80 e que tem na campanha eleitoral de 1989 um marco significativo, quando a tensão contida nos discursos da direita e da esquerda tornase explícita.

Enquanto a direita criticava o "tamanho do Estado" e defendia a desestatização via liberação de atividades para a chamada iniciativa privada, a esquerda criticava a ausência de regulação estatal e defendia a desprivatização do Estado, no sentido de publicizar a sua intervenção.

Derrotada a esquerda, o discurso liberal passa a ser objeto de uma ampla ofensiva através da articulação entre empresários, burocracia estatal e mídia, cujo objetivo parece claro: quebrar a resistência dos setores organizados para integrá-los à sua ordem. Esta ofensiva aconteceu em vários planos.

No âmbito governamental, o projeto de "reconstrução nacional" estabelece a sua meta - "a redução do Estado que deve se dedicar a funções essenciais na área da saúde, educação e infra-estrutura; a liberalização da economia (...) para que o mercado se recomponha e a competitividade alcance níveis internacionais". (Folha de S. Paulo, 15-03-1991). Dentre as medidas de impacto, estavam a reforma administrativa e a privatização das estatais, como foi o caso da USIMINAS, que ocorreu em outubro de 91.

No espaço da mídia, a ofensiva foi centralizada no processo de privatização das estatais. A televisão "trabalhou" os números $e$ os jornais, as pesquisas de opinião. É interessante observar a estratégia da grande imprensa: divulgação ampla do apoio dos operários à privatização das empresas como meio de desqualificação do discurso sindical cutista.

É interessante, também detalhar, a estratégia da imprensa. Baseada numa pesquisa de opinião, ela informava sobre os altos índices de sindicalização na regiāo do ABC demonstrava o apoio dos trabalhadores ao pagamento da dívida externa, as preferências do trabalhador pelo emprego nas empresas multinacionais e, por fim, indicava-os como eleitores de Lula. Boa conclusão: apesar de sindli-

Temáticas, Campinas, 2(3):109-122, jan./jun. 1994 
calizados e de votarem em Lula, os trabalhadores querem a privatizaçāo, o pagamento da dívida e defendem as multinacionais. Ou seja, suas ideologias estão em descompasso com o projeto da esquerda. Mas, não é só isso... no mesmo período tomou conta da imprensa escrita e falada a reportagem dos "homens gabirus" do Nordeste, permitindo majs um alerta: ou operário de multinacional com ideais privatistas ou a saga do "homem gabiru"!

No campo empresarial, pode-se dizer, com base na leitura de Oliveira (1990:45-52), que a “descoberta imprevista” dos anos 90 é o "grau de articulação existente hoje no amplo conjunto das poderosas burguesias no Brasil”. Os vetores desta articulação passam pela fusāo do capital bancário com o industrial; pelas participações do capital estrangeiro nas empresas ditas nacionais; pela simbiose entre empresas estatais produtivas e empresas privadas nacionais e estrangeiras via formação de holding e pela ampliação da organização corporativa dos empresários.

Assim, já integradas na ordem mundial, as burguesias necessitam penetrar todos os espaços de resistência para tornar seu projeto universal e hegemônico. E, para isso, é necessário não apenas ser classe dominante, mas também, e especialmente, classe dirigente.

No Brasil, a década de 80 pode ter sido o cenário da derrota na economia, da ação organizada das classes trabalhadoras, mas certamente não o foi no campo da política. Elas adquiriram uma cara através do novo sindicalismo, da criação da CUT, da formaçāo do PT, de um amplo leque de movimentos reivindicatórios. Enfim, elas construíram formas de alteridade no espaço da resistência e embriōes da ultrapassagem do nível "econômico-corporativo para o das reformas políticas e econômicas". (GRAMSCI, 1988:43)

Se assim é, como então entender a "fertilidade" da construção dessa cultura do operário patrão?

As respostas estariam mais na capacidade que teve o capital de tecer o seu projeto a partir do mundo do trabalho, sob o impulso do discurso modernizador embutido nas saídas da crise, de tratar 
"politicamente" as bases materiais e culturais da sua reestruturação produtiva gestada desde os anos 80 , do que na análise das fragilidades políticas das classes trabalhadoras.

Quais foram as bases objetivas desse processo?

No mundo da prod ução material, temos toda uma reestruturação da produção que, formadora de uma determinada cultura técnica, subsume a resistência do trabalho ao ideário da produtividade e da qualidade total das mercadorias, no interior de uma re-divisão não apenas do trabalho, mas do mercado produtor. Reestruturação essa que captura, psiquica e materialmente, o saber do trabalho como arma da sua própria subordinação, construindo no cotidiano do trabalhador, em cada empresa, uma linguagem de conciliaçōes e salvacionismo da crise face à ameaça do desemprego e do fechamento das fábricas. Entre a diminuição das unidades de produção, a terceirização do trabalho como alternativa de emprego marginal e a solidariedade mercantil entre patrões e assalariados ambos supostamente ameaçados pela recessão - gesta-se um novo projeto para o trabalho, marcado pelo ethos do trabalho subalternizado e consentido. A hegemonia do economico se sobrepõe e tenta massacrar os ideários políticos. Na verdade, a recomposição do trabalhador coletivo se dá não apenas no processo técnico de trabalho, mas no processo político-cultural.

No àmbito da resistência político-institucional dos trabalhadores, captura-se o que de mais caro o movimento organizado conseguiu: a identidade de interesses e as motivações para o "combate". Tornam-se, assim, parceiros do enfrentamento de uma crise que não foi por eles tecida. De interlocutores críticos, conflitivos, tenta-se transformá-los em colaboradores, aliados de um projeto salvacionista de última hora.

No âmbito da subjetividade, procura-se construir uma identidade sobre a suposta equalização dos "prejuízos" da crise para todas as classes. Busca-se a realização de formas subjetivas de consentimento, expressas nas defesas do "mal menor", dos sacrifícios recompensados, da cultura da frente de salvação...

Temáticas, Campinas, 2(3):109-122, jan./jun. 1994 
Neste sentido, as classes dirigentes buscam capitalizar, no âmbito da sua cultura política, as derrotas conjunturais dos movimentos organizados de trabalhadores - principalmente aquelas relacionadas com salários, emprego e poder de decisão - transformandoas em causa e conseqüência da adesão ao projeto da modernidade do grande capital, apostando no sucesso da fragmentação dos interesses imediatos da classe trabalhadora. Isto é, tenta-se socializar a nova e moderna expressão da racionalidade da ordem burguesa: o ideário do cidadão-proprietário ou do operário-patrão, que pode também se transformar no operário-padrão desta sociedade.

REFERÊNCIAS BIBLIOGRÁFICAS

ANDERSON, Perry. As antinomias de Gramsci, São Paulo, Jorués, 1986.

BADALONI, Nicolas. "Gramsci: a filosofia de práxis com revisão", in: HOBSBAWM, E. A história do marxismo. Rio de Janeiro, Paz e Terra, 1991, vol. X.

DIAS, Edmundo F. "Educação e cidadania: classes e racionalidades". in Cadernos da ANDES, no 10, Brasília, 1993.

GRAMSCI, Antonio. Maquiavel, a política e o estado moderno. Rio de Janeiro, Civilização Brasileira, 1988.

JORNAL FOLha DE S. PAULO, 15 de março de 1991.

NETTO, José Paulo. Crise do socialismo e ofensiva medieval. São Paulo, Cortez, 1993.

OLIVEIRA, Francisco de. "Os protagonistas do drama: Estado e Classes Sociais no Brasil”, in: LARANJEIRA, S. (org.) Classes e movimentos sociais na América Latina. São Paulo, HUCITEC, 1990.

REVISTA VEJA, 15 de setembro de 1993.

TAVARES, Maria da Conceição. "Economia e Felicidade", in: Revista Novos Estudos CEBRAP, no. 30, São Paulo, 1991.

Temáticas, Campinas, 2(3):109-122, jan./jun. 1994 